\title{
habitar como horizonte utópico
}

\author{
Rafael Faleiros de Pádua \\ Universidade Federal da Paraiba
}

\section{revista}

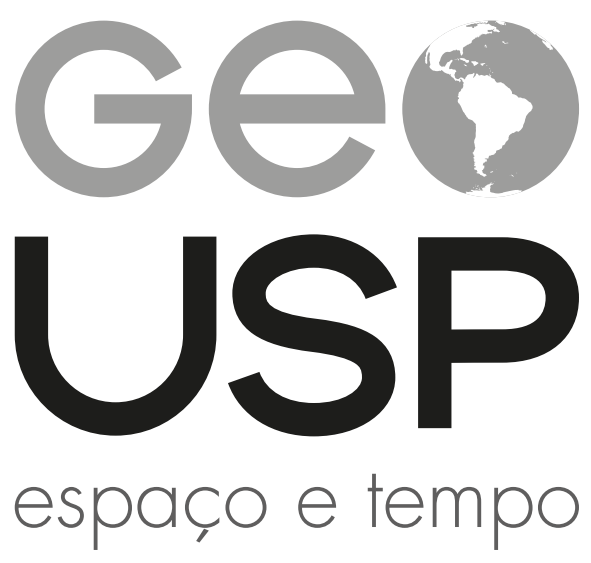

Volume $23 \cdot n^{\circ} 3$ (2019)

ISSN 2179-0892 p. $478-493$

Como citar este artigo:

PÁDUA, R. F. O habitar como horizonte utópico. Geousp Espaço e Tempo (Online), v. 23, n. 3, p. 478-493, dez. 2019, ISSN 2179-0892.

Disponível em: https://www.revistas.usp.br/geousp/article/view/162950. doi: https://doi.org/10.11606/issn.2179-0892.geousp.2019.162950.

\section{(c) $(1)$ (9)}

Este artigo está licenciado sob a Creative Commons Attribution 4.0 Licence 


\title{
O habitar como horizonte utópico
}

\section{Resumo}

$\bigcirc$ artigo procura apresentar o habitar como uma noção filosófica que ilumina os conteúdos da vida urbana e revela suas contradições. Essa noção é pensada como elemento fundamental da produção filosófica do homem, em que tem lugar a necessidade radical de apropriação do espaço para a reprodução da vida. No capitalismo, o espaço se torna mercadoria e objeto de estratégias econômicas, o que reduz o habitar a uma função, o habitat. Nesse contexto, o desafio prático e teórico é recolocar o habitar como possibilidade utópica a partir da realidade funcionalizada do habitat.

Palavras-chave: Habitar. Habitat. Reprodução da vida. Produção do espaço. Urbanização.

\section{The dwelling as a utopian horizon}

\begin{abstract}
The article presents the dwelling as a philosophical notion which illuminates the contents of urban life and reveals its contradictions. This notion is thought as a fundamental element in the philosophical production of mankind, where arises the radical need of spatial appropriation to the reproduction of the life. In capitalism, the space becomes a commodity and object of economical strategies which reduces the dwelling to one function: the habitat. In this context, the practical and theoretical challenge is to relocate the dwelling as a utopian possibility from the functionalized reality of the habitat.
\end{abstract}

Keywords: Dwelling. Habitat. Reproduction of life. Production of space. Urbanization. 


\section{L'habiter comme horizon utopique}

\section{Résumé}

Larticle cherche à présenter l'habiter comme une notion philosophique qui éclaire le contenu de la vie urbaine et en révèle les contradictions. Cette notion est considérée comme un élément fondamental de la production philosophique de l'homme, où se situe le besoin radical d'appropriation de l'espace pour la reproduction de la vie. Dans le capitalisme, l'espace devient une marchandise et un objet de stratégies économiques, ce qui réduit l'habitation à une fonction, l'habitat. Dans ce contexte, le défi pratique et théorique consiste à remplacer l'habiter en tant que possibilité utopique, en partant de la réalité fonctionnalisée de l'habitat.

Mots-clés: Habiter. Habitat. Reproduction de la vie. Production de l'espace. Urbanisation.

\section{Introdução}

De acordo com uma premissa materialista, as noções teóricas só têm sentido se forem contrapostas à prática concreta. Ou melhor, se partirem da prática, ou se contribuírem para explicar essa prática. Nesse sentido, a noção de reprodução ajuda a entender o mundo contemporâneo na medida em que aponta os mecanismos que produzem o movimento da realidade. Na noção de habitar, por sua vez, podemos entender a reprodução a partir de diversas esferas. Reprodução biológica, reprodução da familia, reprodução da força de trabalho, reprodução do espaço urbano etc. Podemos definir o tempo contemporâneo como o momento da reprodução, porque parece que o modo de produção capitalista totalizou de tal maneira a vida da sociedade que suas determinações (sua realização) parecem constituir o movimento da própria sociedade. Assim, a reprodução da sociedade é ao mesmo tempo a reprodução do modo de produção capitalista, que conquistou a vida cotidiana, a cidade, o urbano e o espaço da vida. Podemos entender a reprodução nos atos da vida cotidiana, e é aí que a teoria ganha consistência, na prática, sendo ela mesma uma prática. Neste artigo desenvolveremos algumas notas que procuram entender o habitar como irredutibilidade do humano, portanto, necessidade prática e também um horizonte utópico, dado que na urbanização capitalista são produzidas barreiras para sua realização. $\bigcirc$ habitar é, portanto, também uma necessidade teórica, de uma teoria próxima da prática, que possa construir um projeto de sociedade que supere as contradições e persiga a apropriação concreta do espaço pelo homem.

\section{A reprodução e o habitar}

Observemos um conjunto habitacional na periferia de uma grande cidade brasileira. Mais de mil e duzentas unidades de apartamentos de 40 metros quadrados. A região onde foi construído 
era antes zona rural, nas franjas do tecido urbano. A distância para o centro da cidade é de muitos quilômetros, o transporte coletivo é demorado e de baixa qualidade. Há poucos serviços nas proximidades, dado que é um espaço urbano em formação. Apesar disso, mil e duzentas familias foram habitar esse conjunto habitacional. Para as familias, essa foi a possibilidade de acesso à moradia própria. Mas trata-se de uma moradia produzida em série, de modo a maximizar o aproveitamento do terreno para a produtividade dos rendimentos de seus produtores privados. A moradia se reduziu, degradou-se em mercadoria, e o habitar se reduz ao habitat. $\bigcirc$ espaço exíguo da moradia é um espaço fundamental da reprodução da família, mas, tornado mercadoria, ele se reduz ao mínimo, ao lugar de dormir, de comer, muito pouco o lugar de se viver, de se constituir a privacidade necessária para a vida. Mas se vive ali, as famílias constroem suas vidas ali, se reproduzem. $\bigcirc$ apartamento não tem nada de particular de cada família, é padronizado, é um espaço homogêneo. Mas cada familia torna seu espaço próprio, habitável. Do espaço da reprodução econômica e política do espaço concebido, homogêneo, vazio, para o espaço vivido da reprodução da vida das familias há uma diferença importante. $\bigcirc$ uso preenche o vazio, constrói um conteúdo de precariedade e realização na reprodução da família. É ao mesmo tempo o espaço empobrecido, pequeno, apertado, mas também o espaço da vida, da conquista da casa, que imporá novos problemas cotidianos: o acesso à cidade, a distância ao trabalho, a falta de espaço, a distância aos comércios maiores etc.

Assim, o espaço revela também a reprodução. A própria paisagem ou a morfologia do espaço de um conjunto habitacional, ou de um condomínio fechado, ou de uma região verticalizada, evidenciam a homogeneização das formas, assim como apontam a homogeneização dos conteúdos, das relações sociais. A produção do espaço como mercadoria é a concretização da reprodução do valor por meio do espaço, mas esse espaço produzido é o lugar da vida da sociedade. As relações sociais que se desenvolvem no espaço são o conteúdo desse processo de reprodução também do espaço segundo determinações gerais do modo de produção. Ou seja, tanto as formas espaciais como as formas sociais serão fruto desse processo de reprodução, dessa generalização de determinadas práticas de produção e de vida do/no espaço. Embora seja preciso discernir os agentes hegemônicos da produção do espaço (assim como os não hegemônicos), é a sociedade como um todo que produz o espaço por meio dos conflitos e das contradições que nele se materializam concretamente. $\bigcirc$ nível das relações sociais, das práticas, evidencia essa materialização das contradições.

Desse modo, a reprodução social é a continuidade das determinações sociais totalizadoras criando continuamente suas possibilidades (ou impossibilidades) de continuidade. Muitas vezes esse processo se descontinua, tem crises, explicita as contradições. Essa reprodução social se dá também por meio do espaço, evidenciada nas morfologias do conjunto habitacional da periferia, nos condomínios fechados, nas regiões de verticalização, nas favelas etc. É pela produção e reprodução do espaço que as relações sociais vão se delineando, que um cotidiano ou um infracotidiano são conformados. Com isso, é o espaço e a própria reprodução da vida que vão sendo perpassados pelas determinações da lógica da mercadoria, que vai configurando formas de apropriação e de uso do próprio espaço.

\section{Reprodução do capital x reprodução da vida}

É preciso ter clareza, no entanto, de que a lógica da mercadoria não diz tudo sobre a reprodução da vida. As determinações da lógica da mercadoria condicionam cada vez mais a 
reprodução da vida, mas esta não se reduz àquela. As contradições evidenciam que a reprodução da vida é também apropriação concreta do espaço, não somente vivência das privações ou das possibilidades contidas no interior da lógica da mercadoria. Existem subversões à lógica, negações às privações programadas, concebidas nos planos do político-institucional e do econômico. Insurgências no nível da vida concreta despontam cotidianamente nos espaços da privação, no interior do processo de segregação socioespacial. Nesse sentido, o espaço concebido do conjunto habitacional como um espaço controlado, programado, foge também às programações e se preenche de formas de apropriação concreta da realização da vida. A partir dessa questão, podemos dizer que a reprodução nunca é reprodução ou repetição pura, mas contém em si sua negação, ou seja, também é produção de algo, também é criação.

A partir de Heidegger e de Bachelard, Lefebvre (1965) mostra que o habitar não é mecânico, operacional, e que, no entanto, é transformado num conjunto de técnicas, de otimização das ações cotidianas, tornado um objeto econômico. É reduzido, degradado, funcionalizado, restrito à função de o indivíduo se alojar em algum lugar, e não propriamente de habitar um lugar. Mas surge aí uma contradição, que é a necessidade (radical) de habitar, a profundidade exigida dos conteúdos do habitar nas condições impostas pela superficialidade do habitat. Retomando Heidegger, Lefebvre associa o habitar ao ser do homem, ou seja, o habitar faz parte da condição humana, do processo de humanização do homem.

Há, segundo ele [Heidegger], uma relação entre o construir, o habitar, o pensar (e o falar). O habitar em sua essência é poético. É um traço fundamental da condição humana, e não uma forma acidental ou uma função determinada. Comentando o admirável poema de Hölderlin, "Poeticamente habita o homem", Heidegger declara que a palavra do Poeta não concerne em nada às atuais condições da habitação. Ela não afirma que habitar queira dizer se alojar. Nós nos encontramos, diz Heidegger, diante de uma dupla exigência e de um duplo movimento: pensar a existência profunda do ser humano partindo do habitar e da habitação-pensar o ser da Poesia como um "construir", como um "fazer habitar" por excelência (Lefebvre, 1965, p. 5, tradução nossa).'

Por isso o habitar como necessidade irrompe no habitat, contraditoriamente, expondo a degradação do habitat. Por isso o habitar não pode ser reduzido a cálculos, às prescrições exatas dos planejadores, porque se coloca como produção propriamente humana, a partir das necessidades do homem em seu processo de humanização e não a partir de concepções apriorísticas do que deve ser o morar, o habitat.

1 "Il y a selon lui un lien entre le bâtir, l'habiter, le penser (et le parler). L'habiter, dans son essence, est poétique. C'est un trait fondamental de la condition humaine, et non une forme accidentelle ou une fonction déterminée. Commentant l'admirable poème de Hölderlin, 'Poétiquement habite l'homme', Heidegger déclare que la parole du Poète ne concerne en rien les conditions actuelles de l'habitation. Elle n' affirme pas qu'habiter veuille dire se loger. Nous nous trouvons, dit Heidegger, devant une double exigence et un double mouvement: penser l'existence profonde de l'être humain en partant de l'habiter et de l'habitation-penser l'être de la Poésie comme un 'bâtir', comme un 'faire habiter' par excellence" (Lefebvre, 1965, p. 5). 


\section{O habitar e a pesquisa sobre o vivido}

No prefácio do texto da pesquisa sobre o habitat pavillonnaire, ${ }^{2}$ realizada por um grupo de pesquisadores franceses, Lefebvre mostra uma contradição importante, que é a crescente operacionalização daquilo que não é operacional, que é o habitar. Nesse ponto do texto, ele remete novamente a Heidegger, pois este já apontava essa condição do habitar. Pensando o habitar concretamente, ele implica a criação de uma realidade humana como realização da vida em suas potencialidades. Nesse sentido, podemos pensar que se trata do homem e do espaço da vida do homem como finalidade e não como mediação de interesses alheios à realização da vida humana.

Por sua vez, discutindo a metodologia de pesquisa para alcançar os conteúdos do habitar, Lefebvre (1965, p. 13, tradução nossa) indica que a técnica do questionário não é adequada, pois:

[...] só a entrevista não diretiva pode atingir o habitar. É preciso dar a palavra aos interessados, orientando a entrevista para a atividade específica que o entrevistador estuda (aqui, o habitar), mas deixando livre a expressão. ${ }^{3}$

Aqui há um elemento metodológico importante, que é o "dar a palavra aos interessados", para que eles falem livremente sobre o habitar como atividade primordial da vida. $O$ fato de Lefebvre ressalvar que o questionário fechado não alcança o habitar revela a preocupação de abarcar a vida concreta, com seus problemas e suas possibilidades. $O$ habitar se revela aí como um sistema parcial que é também um conjunto de sistemas parciais, entendendo sistemas aqui como sistemas abertos, nunca fechados. É o nível do morar, mas também o modo como se vive a cidade. A casa é um elemento fundamental da vida, referência importante da vida urbana, mas ela deve ser pensada na sua relação com a cidade. Assim, o habitar não se reduz ao âmbito da casa, mas se expande ao âmbito da vida na cidade, à vida urbana, e a pesquisa sobre o habitar se pretende uma pesquisa sobre o modo como se vive concretamente a cidade, tendo como referência fundamental a casa, o espaço mais íntimo, mas também a cidade e o espaço público, do encontro, da reunião. Nesses termos, é da prática concreta que estamos falando, ou seja, trata-se de uma pesquisa que busca alcançar essa prática.

Para ele, "[o]s questionários objetivos não vão longe. As entrevistas não diretivas vão mais profundo nos 'seres humanos'” (Lefebvre, 1965, p. 13, tradução nossa). ${ }^{4}$ E, um pouco adiante, complementa:

Aqui, nós propomos uma orientação. A entrevista, necessária, não basta. [...] A descrição minuciosa é importante: aquela das casas, dos bens móveis e imóveis, das vestimentas, dos aspectos e dos comportamentos. Só o confronto entre dados sensíveis tal como os percebe o sociólogo e como procura compô-los como conjunto, de um lado, e, de outro, os lugares, os tempos e as coisas percebidas pelas partes interessadas permite um conhecimento. [...] $\bigcirc$ sistema de objetos

2 Habitat pavillonnaire é a moradia unifamiliar padronizada localizada nos subúrbios das grandes cidades, que na França ganhou força como forma de moradia em meados do século xx (Géoconfluences, [s.d.]).

3 "seul l'entretien non-directif peut atteindre l'habiter. Il faut donner la parole aux intéressés, en orientant l'entretien sur l'activité spécifique que l'enquêteur étudie (ici l'habiter) mais en laissant libre l'expression" (Lefebvre, 1965, p. 13).

4 "Une grande difficulté méthodologique surgit ici. Les questionnaires, précis, ne vont pas loin. Les entretiens non-directifs vont plus profond dans les 'êtres humains'” (Lefebvre, 1965, p. 13). 
permite identificar e analisar o sistema das significações verbais, e reciprocamente (Lefebvre, 1965, p. 13, tradução nossa). ${ }^{5}$

Dessa forma, há a necessária aproximação com a vida concreta e suas necessidades e desejos, propriamente humanos, o que remete à noção de apropriação:

A apropriação não destrói, mas transforma a natureza - o corpo e a vida biológicos, o tempo e o espaço dados - em bens humanos. A apropriação é o objetivo, o sentido, a finalidade da vida social. Sem a apropriação, a dominação técnica da natureza tende ao absurdo pelo crescimento. Sem a apropriação, pode haver crescimento econômico e técnico, mas o desenvolvimento social propriamente dito permanece nulo (Lefebvre, 1965, p. 17, tradução nossa). ${ }^{6}$

Em Tempos equívocos, Lefebvre (1976) se define como alguém das margens em diversos aspectos, entre eles porque transitava por diversos domínios da filosofia e da ciência, não se fixando unicamente em nenhum dos campos; outro aspecto relevante dessa sua marginalidade está no fato de trabalhar filosoficamente e sociologicamente temas não tão presentes nas reflexões filosóficas. Sua preocupação com o cotidiano, por exemplo, ilustra muito bem essa aproximação com temas marginais nas preocupações da Filosofia. Suas pesquisas sobre o cotidiano, assim como aquelas sobre o espaço e sobre o urbano, revelam a tentativa de trazer ao conhecimento teórico as questões que afetam a vida concreta. Nessa perspectiva, é o mundo concreto, com seus problemas concretos, que deve ser interpretado, entendido, elevado ao nível do conhecimento teórico, para que se possa pensar um projeto de transformação da sociedade por meio de um novo humanismo. Nesse sentido, é a prática (práxis) o terreno e o objeto do conhecimento. É o movimento da prática socioespacial concreta que o movimento do pensamento procura acompanhar, interpretar, entender e transformar. Com isso, o próprio conhecimento tem uma necessária implicação com a prática, ele próprio faz parte da prática, pois é político e tem como finalidade projetar uma nova sociedade a partir das possibilidades postas na realidade. Por isso, são do maior interesse e mesmo necessárias as reflexões teóricas sobre os espaços-tempos da vida cotidiana. Para Lefebvre (1991), o pensamento é prático, social e histórico, portanto sempre em movimento e em articulação com o movimento da realidade. Nesse sentido, trata-se de um pensamento aberto, não dogmático, que busca "pensar o homem empírico [...]: o homem das necessidades, o homem insatisfeito e satisfeito" (Lefebvre, 2008, p. 596).

\section{Apropriação e habitar}

5 "Ici, nous proposons une orientation. L'entretien, nécessaire, ne suffit pas. [...] La description minutieuse est importante: celle des maisons, des biens meubles et immeubles, des vêtements, des visages et des comportements. Seule la confrontation entre les données sensibles, telles que les perçoit le sociologue et telles qu'il cherche à les saisir comme ensemble, d'une part, et d'autre part les lieux, les temps et les choses perçues par les intéressés, permet une connaissance. [...] Le système des objets permet de cerner et d'analyser le système des significations verbales et inversement" (Lefebvre, 1965, p. 13).

6 "L'appropriation ne ravage pas, mais transforme la nature - le corps et la vie biologiques, le temps et l'espace donnés - en biens humains. L'appropriation est le but, le sens, la finalité de la vie sociale. Sans l'appropriation, la domination téchnique de la nature tend vers l'absurdité en s'accroissant. Sans appropriation, il peut avoir croissance économique et technique, mais le développement social proprement dit reste nul" (Lefebvre, 1965, p. 17). 
A preocupação com a prática socioespacial remete à noção de apropriação, que é fundamental para pensarmos o habitar. Ela é o sentido da prática social, segundo Lefebvre (1965, p. 17, tradução nossa), para quem "a cidade de outrora (antiga ou medieval) trouxe uma apropriação espontânea, limitada mas concreta, do espaço e do tempo". ${ }^{7} \mathrm{Na}$ cidade moderna, porém, com a degradação do habitar em habitat, a apropriação tem problemas para se concretizar. A apropriação tem o sentido de realização plena da vida, realização da totalidade do homem nos atos concretos da vida. À medida que a prática concreta vai sendo fragmentada, que os espaços-tempos da vida vão sendo funcionalizados, essa realização plena do homem também tem dificuldades para ser alcançada.

Na cidade moderna, sobretudo na cidade contemporânea, o espaço da vida passa a ser objeto de estratégias que o produzem com finalidades determinadas. $\bigcirc$ uso concreto do espaço passa a ser mediado pela lógica da mercadoria, já que o espaço, pela mediação da propriedade privada da terra, se torna uma mercadoria. Assim, o espaço é produzido estrategicamente, tendo como finalidade prioritária não o uso, mas sua realização como mercadoria, pela realização do valor de troca. Nesse processo, a dominação do espaço se sobrepõe à apropriação do espaço, e mesmo a moradia, espaço fundamental da reprodução da vida, entra no circuito da troca mercantil. Assim como a de apropriação, a noção de habitar colocam a realização do homem como finalidade da prática social. No entanto, à medida que o uso concreto do espaço vai sendo submetido à mediação da troca, a finalidade da prática social passa a ser algo alheio à realização do homem, subsumindo-se à realização (prioritária) do espaço como mercadoria.

Nessa nossa proposição de trabalhar conjuntamente o habitar e a prática socioespacial, queremos chamar atenção para a preocupação de Lefebvre com o concreto, com a vida, com a materialidade. Por isso nessa discussão alguns conceitos têm bastante importância, como os de apropriação e de alienação. É preciso buscar os conteúdos da alienação, que é concretamente vivida. $\bigcirc$ habitar, por sua vez, se revela como a prática social desalienada, concreta. $\bigcirc$ habitar se situa na esfera da obra, pois ele é criação permanente, ele é apropriação. No capitalismo, o espaço se torna mercadoria e, portanto, o habitar se degrada, reduz-se em habitat. Enquanto o habitar, como dissemos acima, é da esfera da obra, o habitat é da esfera do produto. $\bigcirc$ habitar se degrada em habitat à medida que a riqueza do habitar vai sendo fragmentada em pedaços, quando a vida cotidiana vai se compartimentando em espaços-tempos específicos. Essa degradação se dá quando o espaço se torna objeto de estratégias da reprodução das relações de produção, quando a racionalidade técnica entra na prática modificando-a, produzindo uma nova prática. $\bigcirc$ urbanismo, como conhecimento técnico que domina a prática, funcionaliza os espaços da vida, fragmenta o espaço e consequentemente seu uso, molda uma prática. Essa transformação se dá com a generalização de uma prática industrial sistematizadora dos espaços e da vida, cuja realização acontece sob a mediação fundamental do Estado.

\section{O habitar e as estratégias espaciais: a crise da cidade}

O habitar é muito mais amplo que o simples morar em algum lugar, do que o se alojar em determinado espaço. $\bigcirc$ habitar vai muito além do habitat, que é um aspecto do habitar, aquele

7 "la ville d'autrefois (antique ou médiéval) apporta une appropriation spontanée, limitée mais concrète, de l'espace et du temps" (Lefebvre, 1965, p. 17). 
restrito à funcionalidade de morar num espaço definido. $\bigcirc$ habitar tem um sentido de totalidade, de realização da humanidade do homem no espaço. É o espaço da apropriação, da realização do homem em todas as suas potencialidades. No entanto, a apropriação se confronta com a dominação do espaço, que é a transformação do espaço em objeto estratégico do Estado (político) e do econômico. Gradativamente, o espaço se torna mediação para a resolução das crises do capital. O setor imobiliário, de setor periférico da economia, torna-se cada vez mais central para a reprodução econômica. A produção de mais-valor passa, assim, pela produção do espaço em suas diversas modalidades: espaços de infraestruturas, espaços de moradia, espaços institucionais etc. As estratégias espaciais ganham destaque no conjunto das estratégias do político e do econômico. Com isso, o espaço é esquadrinhado, normatizado, controlado, parcelado e vendido aos pedaços. $\bigcirc$ espaço é tomado como uma mercadoria e seu uso passa a ser mediado pela lógica da mercadoria. No entanto, não é uma mercadoria qualquer, pois é também o lugar da reprodução da vida, é o lugar do habitar. Uma contradição do espaço, mais geral, impõe-se na prática, que é o espaço produzido e mediado pela lógica da mercadoria, controlado pelo aparato estatal, ou seja, lugar da reprodução do valor, e o espaço como lugar da reprodução da vida em todas as suas dimensões. $\bigcirc$ habitar reduzido ao habitat revela essa contradição entre a lógica do valor de troca e a lógica do uso.

$\bigcirc$ uso concreto do espaço é então submetido ao valor de troca, mas, como dissemos acima, o espaço não é uma mercadoria qualquer, pois também é mediação fundamental para a reprodução da vida. Nesse sentido, ele não se realiza como uma mercadoria pura, puro valor de uso-valor de troca, mas manifesta sempre o seu uso para além da mediação do valor de troca, para além de sua condição de mercadoria. Nesse sentido, o habitar sempre se imiscui no habitat. A reprodução da vida como necessidade radical sempre impõe alguns grãos de apropriação no reino da dominação. A aridez do habitat nunca é total, mas é contradição entre a dominação que se impõe e a apropriação necessária à reprodução da vida. Essa contradição é vivida na prática socioespacial, é nesse nível que ela pode ser identificada e pensada. Aos mais pobres, a aridez dos conjuntos habitacionais da periferia, as enormes distâncias cotidianas entre a casa e o trabalho, a falta de lazer, a vida restrita a moradias extremamente pequenas, a falta de acesso aos espaços centrais da cidade, a dependência de um transporte coletivo ineficiente, a dificuldade em resolver os dilemas práticos da vida cotidiana (compras, saúde, educação) etc. Por outro lado, aos mais abastados, a extrema dependência do automóvel, o autoenclausuramento em moradias (verticais ou horizontais) fortificadas, a fragmentação dos espaços-tempos da vida na cidade etc. Ou seja, de modos diferentes, a contradição entre o espaço como lugar da reprodução do valor e o espaço como lugar da reprodução da vida é vivida pelo conjunto da sociedade, embora a classe mais pobre sofra de maneira mais radical, mais urgente a vida mediada pela lógica abstrata da acumulação econômica. ${ }^{8}$ Diante disso, verificamos que há uma crise da cidade que é generalizada, pois há uma dificuldade de realização da cidade como lugar da sociabilidade dos diferentes. Um dos indícios dessa crise é que o modo de vida urbano é cada vez mais transformado por uma lógica de condomínio fechado, cuja realização se baseia no discurso da violência contemporânea.

8 Cabe a ressalva de que, embora também experimentem a fragmentação da vida na cidade, as classes mais abastadas são em grande medida beneficiárias desse processo, ao menos no sentido econômico, revelando-se a luta de classes no processo de produção social da cidade. 
Essa lógica, produzida em grande medida pelas estratégias dos agentes hegemônicos da produção do espaço, não resolverá o problema da vida com segurança na cidade e, pelo contrário, aprofundará o problema, na medida em que se trata de uma negação violenta da cidade como espaço público.

A preocupação com o habitar, nesse sentido, é a preocupação com a vida concreta na cidade. Revela a necessidade de pensar a cidade como o lugar concreto da vida para além da cidade como mediação da reprodução do valor. Coloca a necessidade de se pensar os conteúdos concretos da luta de classes no contexto da vida urbana.

\section{O habitar e o processo de industrialização-urbanização}

Outros momentos da história revelaram o habitar como apropriação concreta do espaço urbano. Na cidade grega, o espaço público, a ágora, era o espaço do exercício da política direta. $\bigcirc$ cidadão 9 tinha responsabilidade pelas decisões que determinavam a vida da cidade, e o debate e as decisões transcorriam no espaço público. $\bigcirc$ estatuto de cidadão, inclusive, estava ligado ao pertencimento ao espaço da cidade. Na cidade medieval, o desenvolvimento da praça do mercado revela um lugar da troca mercantil, mas onde se faziam muitos outros tipos de trocas concretas. Dessa forma, o que acontecia ali transcendia em muito a mera realização da troca mercantil, pois também afirmava relações pessoais, manifestações artísticas, festas, reuniões dos diferentes. Muitas cidades nasceram no entorno da praça do mercado. Essas são referências históricas que mostram elementos concretos do urbano, revelando o espaço urbano como apropriação. São referências, portanto, do habitar. Na cidade industrial, há uma transformação profunda nos modos de produzir e usar a cidade.

A indústria, ao se desenvolver, toma a cidade preexistente, domina-a e a transforma. Para Lefebvre, o processo de industrialização é muito mais que a produção de mercadorias na fábrica, pois é também uma transformação social, assim como uma transformação no espaço. É tomando a cidade que a industrialização poderá realmente se desenvolver, pois na cidade se encontram as condições para esse desenvolvimento, como a concentração da população (mercado de mão de obra e consumidores), a concentração de comércios para a circulação das mercadorias, a centralidade em seus diversos aspectos.

Portanto, mesmo que a indústria tenha iniciado suas atividades fora das cidades, é nelas que ela realmente florescerá e se desenvolverá. Nesse desenvolvimento, no entanto, a industrialização destruirá a cidade preexistente, imporá a sua lógica, e seu ritmo, transformará a cidade radicalmente. Trata-se do processo de implosão-explosão da cidade, no qual o centro histórico perde relativamente seu sentido de centralidade e novas centralidades surgem na cidade e quando o tecido urbano se expande desmesuradamente. Assim, a cidade vai sendo produzida segundo as necessidades da reprodução da indústria, que por sua vez é também a expansão da lógica da mercadoria como mediação para o uso do espaço. No texto "As grandes cidades", de A situação da classe trabalhadora na Inglaterra, Engels (2008) descreve as péssimas condições de vida e habitação da classe operária no século xix nas grandes cidades inglesas. Ali já

9 Embora apenas uma pequena parcela da população fosse considerada cidadã - em Atenas, os homens acima dos 18 anos, atenienses, filhos de pai e mãe atenienses. 
estava evidente como a indústria transformava a cidade ou que cidade a indústria produzia. Era evidente também que a reprodução da vida dos trabalhadores se subordinava à realização da mercadoria, que se impunha como finalidade central do processo de industrialização. Nesse sentido, a própria cidade e os espaços da vida cotidiana na cidade passam a estar subordinados

à lógica da mercadoria. É assim que o habitar vai sendo degradado, reduzindo-se a um habitat, à sobrevivência precária na cidade.

Mas se por um lado a industrialização degrada a vida na cidade, por outro ela induz a urbanização da sociedade. Dessa forma, a partir do século xx, quando a industrialização se generaliza, expandindo-se para outras partes do planeta, induzindo a uma urbanização também na escala do planeta, constitui-se uma problemática urbana, que ilumina o modo como se vive nas cidades. A problemática urbana envolve uma contradição, que é aquela em que a industrialização induz a urbanização, mas destruindo os elementos do urbano da cidade preexistente, ${ }^{10}$ pois, segundo Lefebvre (2006), o urbano é a forma da reunião das diferenças, da simultaneidade. Trata-se de uma expansão da urbanização (ou seja, das possibilidades para a constituição do urbano), mas de maneira a separar os elementos do urbano, a promover a fragmentação do espaço (pela mediação da propriedade privada da terra) e a segregação socioespacial. Contraditoriamente, é no contexto de controle e programação do espaço e do habitar que se ergue a sociedade urbana.

Para Lefebvre, a industrialização é do âmbito do quantitativo e promoverá um crescimento do tecido urbano, uma expansão da urbanização, mas a urbanização é do âmbito do qualitativo, ou seja, refere-se ao modo como se se apropria do espaço. A urbanização, de induzida, torna-se indutora do processo social, e com isso, trata-se de pensarmos as possibilidades de apropriação que se colocam nesse processo. A hipótese estratégica de Lefebvre é a de que a sociedade urbana é a superação da sociedade industrial, e que uma racionalidade urbana substituirá a racionalidade industrial, produtivista, calculista, quantitativa, que busca o crescimento econômico. A racionalidade urbana, por sua vez, busca o desenvolvimento social, o qualitativo, a apropriação. É nesse contexto que podemos pensar numa recuperação do habitar.

A problemática urbana ilumina também o fato de que a vida urbana se coloca como uma condição inescapável nesse momento da história. Nesse sentido, é preciso enfrentar os desafios colocados pelo processo de urbanização. Esses desafios são próprios da prática socioespacial, são relativos ao modo como se vive a cidade e o urbano hoje. Ou seja, referem-se à preocupação com o habitar.

\section{O habitar e o Estado}

Como já indicamos acima, o habitar passa a ser objeto de estratégias. Passa a ser controlado, produzido segundo padrões e modelos. $\bigcirc$ habitar compreende os espaços de apropriação para além daquele da casa, pois avança para os espaços próximos à casa e para a cidade toda. É quando a cidade é um lugar familiar, apropriável pelo cidadão. $\bigcirc$ habitar, que é essencialmente obra, ao se tornar produto, é reduzido a um de seus sistemas parciais, que é o habitat. Para as diversas classes sociais, o habitat é projetado e manejado com a finalidade de maximizar lucros

10 Produz uma urbanização desurbanizante, como escreve Lefebvre em $O$ direito à cidade. 
na produção da moradia. Nesse processo, o sentido filosófico do habitar como obra é perdido, reduz-se e não permanece senão como resíduo. $\bigcirc$ habitar é, assim, reduzido a uma função, o alojar-se em algum lugar, distanciando-se do horizonte do habitar como obra, como criação permanente, como apropriação concreta do espaço. Produz-se, então, um espaço abstrato que não leva em consideração todas as potencialidades criadoras da humanidade, pois trata-se de um espaço dominado pela lógica estatal e econômica.

A política do espaço apenas o concebe como meio homogêneo e vazio, no qual se estabelecem objetos, pessoas, máquinas, locais industriais, redes e fluxos. Tal representação fundamenta-se numa logística de uma racionalidade limitada, e motiva uma estratégia que destrói, reduzindo-os, os espaços diferenciais do urbano e do "habitar" (Lefebvre, 2002).

$\bigcirc$ Estado domina o espaço, produzindo um espaço abstrato. Trata-se da imposição de uma racionalidade industrial que transforma as necessidades humanas concretas em objetos para a valorização econômica, com o controle e a programação das necessidades pela técnica e pela ciência. Num plano mais amplo, o urbanismo se coloca como instrumento do Estado, como técnica de programação dos modos de uso do espaço.

Conforma-se um cotidiano programado e o habitar aparece aí reduzido a habitat, como a esfera do espaço privado, da moradia. Num espaço-tempo todo fragmentado, o habitat se coloca como o resíduo de intimidade, de apropriação, aquilo que sobrou do habitar. $\bigcirc$ habitat é objeto de cuidados, de estratégias. É programado, projetado e produzido como um produto, em série. morar em algum lugar perde substância na medida em que o lugar de moradia é padronizado. O morar, o comer, o vestir, o pensar passam também por uma padronização. $\bigcirc$ espaço é tomado, portanto, por essa padronização. Grandes parcelas do espaço são fechadas nos condomínios. Uma vida cotidiana totalmente dependente do carro, fechada em lugares fechados e pagos; os condomínios-clube, que também ocupam grandes espaços na cidade, apresentam-se como "oásis" de lazer e segurança no interior da cidade "caótica"; para os mais pobres, a moradia é a precariedade da autoconstrução na periferia ou em ocupações e favelas, onde o morar se reduz às mínimas condições de abrigo e privacidade. Assim, é generalizado o fato de que há uma redução dos conteúdos do habitar para a realização do habitat.

\section{O habitar, a noção de produção e o vivido}

Merece atenção no pensamento de Lefebvre a noção de produção, que não tem apenas o sentido de produção econômica de coisas, mas se trata de produção em sentido amplo. É a produção como produção do homem, produção da sociedade e dos elementos necessários à reprodução do homem. Nesse sentido, produção é a criação das condições de reprodução do próprio homem, atividade criadora, prática criadora. No entanto, à medida que os processos abstratos da reprodução da acumulação ampliada do capital dominam a produção, o homem torna-se passivo nesse processo de reprodução. Finalidades exteriores dominam a própria reprodução do homem, condicionando essa reprodução a mediações abstratas. É nesse contexto que podemos entender a redução do habitar a habitat. $\bigcirc$ habitar remete à apropriação, portanto, à 
criação, à produção de um espaço de apropriação. $\bigcirc$ habitat, por sua vez, é a funcionalização do habitar, a sua redução a um de seus sistemas parciais que é o morar, o ocupar um lugar. A sociedade industrial, com sua prática sistematizadora, afirmará o habitat como modo de viver no urbano. Ou seja, conformará uma vida urbana precária, parcial, fragmentada, empobrecida. Mas a realidade não se fecha nessa parcialidade, e a apropriação sempre se coloca como possibilidade, mesmo onde ela parece distante. Elementos do habitar surgem na aridez do habitat, revelando as possibilidades de uso concreto do espaço.

Pensar o espaço pode ser sinônimo de pensar o vivido, pois o espaço é dimensão fundamental da vida. $\bigcirc$ vivido concreto apresenta um desafio a ser enfrentado pelo pensamento. A realidade (e, consequentemente, o espaço), nesse momento da modernidade, transforma-se com uma velocidade acelerada que nunca houve antes. Os conteúdos se transformam nesse processo de transformação. $\bigcirc$ desafio é justamente apreender esses conteúdos. Nas grandes cidades e aglomerações urbanas, o processo de transformação significa a destruição-reconstrução de parcelas do tecido urbano, assim como a expansão do espaço urbano com a construção de novos espaços periféricos. Pensar o habitar nesse momento é pensar como se vive concretamente nos espaços periféricos, nos conjuntos habitacionais gigantescos ou nos condomínios fechados, ou ainda nos condomínios-clube que negam a cidade. É pensar como se vive nas favelas e mesmo nas ruas, onde o habitar se perde na privação quase total de apropriação. $\bigcirc$ modo de vida urbano hoje implica pensar as desigualdades e as contradições que estão no espaço urbano, produzidas pelo mesmo processo de reprodução social que realiza o espaço como mercadoria. De um lado a privação total, de outro, formas de uso do espaço fabricadas, em espaços fabricados em série, numa padronização definida alhures, com mais ou menos acesso aos equipamentos urbanos. A cidade como lugar de encontro das diferenças se obscurece numa cidade que é o encontro das desigualdades indiferentes, que se enfrentam em contradições, mas se reproduzem, produzindo novas contradições. É importante ressaltar que as contradições são concretamente vividas na cidade, e é nesse nível do vivido que podem ser apreendidas.

\section{O habitar como apropriação concreta do espaço}

Podemos buscar na literatura exemplos do habitar a cidade a partir de um lugar da cidade. Selecionamos dois trechos nos quais podemos entender a apropriação concreta do espaço, um de Mario Benedetti sobre um bairro de Montevidéu, e um de Naguib Mahfuz sobre um lugar na cidade do Cairo. Diz Benedetti (1998, p. 43-44):

Sim, Capurro era um conglomerado de bairros, quase uma republiqueta. Por algum motivo, a tendência dos seus habitantes era ficar por ali, expatriar-se o mínimo possível daquele ambiente familiar em que cada esquina, cada quitanda, cada bar eram como suas próprias casas.

Nesse trecho, o bairro é concretamente vivido pelos habitantes, e os elementos exteriores à casa são como suas extensões. $\bigcirc$ bairro, o espaço público, é assim compartilhado entre os moradores, carregado de referências concretas, vividas. $\bigcirc$ bairro aí tem um aspecto de unidade, é uma totalidade vivida onde os moradores realizam as atividades necessárias à reprodução de 
sua vida. É o lugar conhecido onde, mesmo fora de casa, as pessoas se sentem em casa; há reconhecimento com o lugar e com as pessoas do lugar.

Já Naguib Mahfuz (2002, p. 33, tradução nossa) escreve:

De qualquer forma, teremos vivido na hâra os dias mais intensos de nossa vida, num tempo que, para nós, teve o valor de um momento de eternidade. Nossa vida estava profundamente enraizada nesse lugar; uma vida uniforme mas próspera, que nunca tendeu a se desfazer e a que não faltou um fundamento essencial, situado entre as distrações fúteis e o invisível. ${ }^{11}$

Aqui se trata de um relato do tempo da infância vivido em uma espécie de beco, uma ruela da cidade do Cairo. É interessante a referência que o autor faz ao tempo. A apropriação concreta do espaço expressa uma realização concreta do tempo. Era como se o tempo se eternizasse, e é, nesse sentido, a realização da totalidade do humano naquele espaço-tempo. Há uma ligação profunda com o lugar e, mesmo vivendo uma vida uniforme, havia o sentido da realização, de plenitude. Aqui, trata-se de uma memória do espaço vivido, que remete a um tempo da vida em que o espaço público era o lugar das brincadeiras, de passar o tempo com os amigos, de descobertas. A memória, nesse sentido, não é individual mas plural, porque é compartilhada, é a vivência de uma comunidade, de um reconhecimento coletivo do lugar e entre seus moradores.

Walter Benjamin também mostra elementos do habitar quando escreve sobre Nápoles. Nesse relato, descreve uma cidade sem grandes atrativos, sem referências vistosas, onde o catolicismo tem presença forte, mas com uma forma de religiosidade próxima da vida concreta. É também uma cidade onde falta institucionalidade, numa vida empobrecida em que havia proximidade com a miséria e a doença. Mas o principal desse texto é que ele mostra a cidade como atividade das pessoas, onde nada é definitivo, a cidade é sempre o lugar do novo. Mesmo a arquitetura tinha uma ligação com o ritmo da sociedade.

Segundo Benjamin (1987, p. 147-148):

[a] arquitetura é porosa como essas rochas. Construção e ação se entrelaçam uma à outra em pátios, arcadas e escadas. Em todos os lugares se preservam espaços capazes de se tornar cenário de novas e inéditas constelações de eventos. Evita-se cunhar o definitivo. Nenhuma situação aparece, como é, destinada para todo o sempre; nenhuma forma declara o seu "desta maneira e não de outra". Aqui é assim que se materializa a arquitetura, essa componente mais concisa da rítmica da sociedade.

Há uma mistura entre o que é da esfera privada e o que é da pública. Ambas são lugar de encontros e de abertura para o novo. Segundo Benjamin, ali "[a] vida doméstica é repartida,

11 "Dans tous les cas, nous aurons vécu, dans la hâra, les jours les plus intenses de notre vie, dans une durée qui avait valeur, pour nous, d'un moment d'éternité. Notre vie était profondément enracinée dans ce terroir, une vie uniforme mais épanouie, qui ne tendait jamais à se défaire et que n'était pas dénuée d’un fondement essentiel, situé entre les distractions futiles et l'invisible" (Mahfuz, 2002, p. 33). 
porosa e entremeada [...] [e] cada atitude e desempenho privado é inundado por correntes da vida comunitária" (Benjamin, 1987, p. 152).

Essa mistura entre o público e o privado também fica evidente aí:

Por isso a casa é muito menos o asilo, no qual as pessoas ingressam, do que o reservatório, do qual efluem. Não apenas de portas irrompe a vida. [...] Lides domésticas pendem das sacadas como plantas em vasos. Das janelas dos andares mais altos vêm cestas em cordas para correio, frutas e couve.

Do mesmo modo como o quarto retorna à rua com cadeiras, fogão e altar, a rua peregrina quarto adentro, só que com muito mais rumor (Benjamin, 1987, p. 152-153).

Ou seja, a cidade entra dentro da casa e a casa sai para a rua. A rua, o espaço público é, nesse sentido, extensão da casa, espaço concretamente vivido, apropriado, de modo que os espaços-tempos da vida (casa-trabalho-lazer) não se separam absolutamente.

Outra obra que ajuda a vislumbrar o habitar é o episódio "Adelina" do filme Ontem, hoje e amanhã (1963), de Vittorio De Sica. Esse episódio se passa justamente num bairro pobre de Nápoles, e a trama se desenvolve em torno da personagem Adelina, uma vendedora de cigarros contrabandeados que, para não ser presa, fica grávida continuamente, poucos meses depois de dar à luz o filho anterior. Nessa discussão, o interessante desse episódio é que ele mostra um lugar que é habitado, onde há um sentido de comunidade, onde as pessoas se reconhecem pertencentes ao lugar e se reconhecem entre si, ajudam-se, festejam-se. Quase não se veem carros no bairro, e a rua é espaço do corpo, das brincadeiras das crianças, do encontro dos namorados, das conversas com amigos, é o lugar da compra e venda de inúmeras coisas, do trabalho, enfim, é um lugar de troca concreta. $\bigcirc$ espaço da rua é também o lugar da festa, do compartilhamento das conquistas. Nesse contexto, o momento de trabalho se confunde com a diversão, assim como com a vida privada. Nem o tempo nem o espaço são estritamente fragmentados, funcionalizados, especializados.

Assim, fica evidente que o habitar se realiza na cidade, nos espaços-tempos do encontro, onde se produzem o novo, o inesperado, a totalidade da realização do humano.

\section{O habitar e a produção do espaço}

Pensar o habitar nos direciona para o espaço, para a produção do espaço. $\bigcirc$ espaço, incorporado na reprodução das relações de produção, é ao mesmo tempo hierarquizado, homogeneizado e fragmentado. Trata-se da instalação de um espaço instrumental, abstrato, que fragmenta os espaços-tempos da vida cotidiana. Ao mesmo tempo, é um espaço contraditório, porque revela as contradições da sociedade que o produz. Por sua vez, a cidade é gerida segundo uma racionalidade técnica, como se fosse uma empresa. Essa concepção da cidade e do espaço, colocam barreiras para a apropriação concreta do espaço, para a realização do habitar. $\bigcirc$ habitar, perpassado pela mediação da propriedade privada da terra e pela fragmentação do espaço pelos níveis do político e do econômico, reduz-se a seu aspecto funcional, o habitat. A fragmentação do espaço é fundamental para a instalação do habitat, que revela um modo de vida também 
fragmentado na cidade. A prática socioespacial aí se fecha em espaços delimitados, específicos, funcionalizados. Portanto, uma transformação possível do habitar passaria por uma transformação da sociedade e do espaço na direção de um espaço diferencial, onde os fragmentos sejam reunidos, onde as diferenças se encontrem e a qualidade se sobreponha à quantidade.

\section{Considerações finais: o pensamento e a prática}

A prática socioespacial remete também à ação. Ela encerra não apenas a repetição dos atos banais da vida, mas também a criação, poiesis. Assim, a apropriação emerge na prática, no universo da dominação e da racionalidade técnica. Dessa forma, a prática é passível de ser transformada em uma prática revolucionária, que colocaria como objetivo principal a apropriação, o reino do habitar. Trata-se da possibilidade de retomar o habitar pela prática, agora consciente, agora concreta. $O$ pensamento tem um papel importante aí, que é o de indicar possibilidades e abrir vias, mas é na prática que o processo se realiza. É na prática que se encontram as possibilidades de superação do mundo fragmentado e organizado pela racionalidade técnica.

Estamos diante, portanto, de uma problemática urbana que se impõe praticamente e se coloca como desafio ao conhecimento. Para Lefebvre, trata-se de pensar essa problemática não só a partir do presente e do passado, mas é preciso pensar o futuro, pensar as possibilidades de superar os constrangimentos, as possibilidades de emancipação social presentes na realidade. Poderíamos avançar aqui para as possibilidades de alcançar o habitar. A dimensão do possível é, portanto, fundamental na obra de Lefebvre. E podemos pensar essa dimensão a partir dos resíduos, daquilo que subverte a lógica da reprodução, a partir dos elementos de apropriação que emergem no universo da dominação. Darei aqui o exemplo de regiões industriais de São Paulo, onde o próprio espaço era dominado por grandes indústrias, mas onde também vivia uma classe operária muito ligada ao ritmo da indústria. Mesmo havendo toda essa dominação do espaço e do tempo pela indústria, nesse contexto havia também momentos de apropriação. A própria concentração de trabalhadores, que se encontravam na fábrica, ou na entrada e na saída das fábricas, ou nos bares das redondezas, gerava momentos de reconhecimento, de reunião, momentos qualitativos do encontro. Por isso, mesmo que a indústria impusesse a sua prática, com seu ritmo, essa prática não se resumia ao movimento do repetitivo imposto por ela (Pádua, 2012). É por meio desses elementos de apropriação que necessariamente se imiscuem no universo da dominação que podemos pensar as possibilidades de outra sociedade, de outro espaço, outra prática, da busca pelo habitar. Dessa forma, no próprio movimento da reprodução se produz algo novo, há a possibilidade de subverter o que está posto em direção a uma superação das barreiras à apropriação.

O pensamento sobre a prática socioespacial se debruça sobre as relações sociais concretas que produzem a sociedade. Assim, ao mesmo tempo em que identifica os nexos, as mediações que fazem com que a realidade se desenvolva, procura também pensar um projeto para essa sociedade, no sentido de superar as contradições postas. Nesse sentido, o conhecimento está implicado na prática, ele também é uma prática e tem um papel central na construção de outra prática socioespacial, outro espaço, outra sociedade. $\bigcirc$ conhecimento tem, assim, uma finalidade, que é mudar a prática, produzir uma crítica e possibilitar a construção de um projeto 
de sociedade. Então, com essa dimensão prática, o conhecimento é essencialmente político, coloca-se ativamente na sociedade procurando mudá-la. Pensando uma superação da realidade fragmentada em direção ao habitar, trata-se de pensar uma mudança radical de perspectiva, na passagem de um pensamento hegemônico calculista, que privilegia a lógica formal e o quantitativo, para um pensamento que enxergue as contradições e vislumbre formas de superá-las. Ou seja, um pensamento que não se apegue à reprodução, mas que busque pensar o novo, um pensamento transformador. Esse processo de superação revela a transformação da prática, de uma prática alienada para uma prática consciente, portanto, capaz de orientar a transformação.

\section{Referências}

BENEDETTI, M. A borra de café. Rio de Janeiro: Record, 1998.

BENJAMIN, W. Obras escolhidas II: rua de mão única. São Paulo: Brasiliense, 1987.

ENGELS, F. As grandes cidades. In: NEGELS, F. A situação da classe trabalhadora na Inglaterra. São Paulo: Boitempo, 2008. p. 67-116.

GÉOCONFLUENCES - glossaire. Habitat pavillonnaire. Disponível em: http://geoconfluences. ens-lyon.fr/glossaire/habitat-pavillonnaire. Acesso em: 4 fev. 2019.

LEFEBVRE, H. La somme et le reste. 4a ed. Paris: Anthropos, 2008.

LEFEBVRE, H. O direito à cidade. 4a ed. São Paulo: Centauro, 2006.

LEFEBVRE, H. A revolução urbana. Belo Horizonte: Ed. UFMG, 2002.

LEFEBVRE, H. Lógica formal, lógica dialética. 5a ed. Rio de Janeiro: Civilização Brasileira, 1991.

LEFEBVRE, H. Tiempos equívocos. Barcelona: Kayrós, 1976.

LEFEBVRE, H. Préface. In: RAYMOND, H.; HAUMONT, N.; DEZES, M.-G.; HAUMONT, A. L'habitat pavillonnaire. Paris: Centre de Recherche de l'Urbanisme, 1965. p. 3-25. MAHFUZ, N. Le vieux quartier. Arles: L'Aube, 2002.

ONTEM, hoje e amanhã. Direção: Vittorio De Sica. Produção: Carlo Ponti. Intérpretes: Sophia Loren, Marcello Mastroianni et al. Roteiro: Alberto Moravia, Eduardo De Filippo, Isabella Quarantotti, Cesare Zavattini, Lorenza Zanuso e Bella Billa. Local: lista de produtores, 1963. 1 filme (118 min.), son., color.

PÁDUA, R. F. Produção e consumo do lugar: espaços de desindustrialização na reprodução da metrópole. Tese (Doutorado em Geografia Humana) - Faculdade de Filosofia, Letras e Ciências Humanas, Universidade de São Paulo, 2012. 